\title{
Diagnóstico del liquen plano oral
}

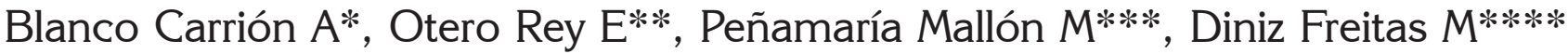

\section{RESUMEN}

El objetivo de este trabajo es presentar los aspectos clínicos y patológicos necesarios para conocer mejor el liquen plano oral y poder diagnosticarlo correctamente.

El diagnóstico se obtiene en primer lugar por el aspecto clínico de las lesiones. Se debe realizar siempre biopsia y estudio anatomopatológico para confirmar la sospecha clínica y realizar diagnóstico diferencial con otras entidades de apariencia clínica similar.

Los pasos que debemos seguir para realizar un diagnóstico de certeza son: estudio de la clínica (anamnesis y exploración clínica), biopsia para estudio histopatológico y analítica sanguínea y determinación de la tensión arterial, buscando una posible relación con determinados procesos sistémicos. Se hará una inmunofluorescencia directa cuando haya que diferenciarlo de dermatopatías similares (lupus, penfigoide o pénfigo). En ocasiones podremos realizar un análisis estructural y otras pruebas diagnósticas.

Palabras clave: Mucosa oral, diagnóstico oral, liquen plano oral.

\section{ABSTRACT}

The aim of this work is to present the clinical and pathological necessary aspects to know better the oral lichen planus and to be able to diagnose it correctly.

The diagnosis is obtained first by the clinical aspect of the injuries. It is necessary to realize always biopsy and histopathologyc evaluation to confirm the clinical suspicion and realize differential diagnosis with other entities of clinical similar appearance.

The steps that we must follow to realize a diagnosis of certainty are: study of the clinic (anamnesis and clinical exploration), biopsy for histopathological study and analytical blood and determination of the blood pressure, looking for a possible relation with certain systemic processes. It will become a direct inmunofluorescence when it is necessary to differentiate it of similar disease (lupus, pemphigoid or pemphigus). In occasions we will be able to realize a ultraestructural analysis and other diagnostic tests.

Key words: Oral mucosa, oral diagnosis, oral lichen planus.

Fecha de recepción: Diciembre 2007.

Aceptado para publicación: Diciembre 2007.

* Prof. Titular de Medicina Oral. Universidad de Santiago de Compostela.

** Doctora en Odontología. Máster Medicina Oral Cirugía Oral e Implantología. Universidad de Santiago de Compostela.

*** Máster Medicina Oral Cirugía Oral e Implantología. Universidad de Santiago de Compostela.

**** Doctor en Odontología. Master Medicina Oral Cirugía Oral e Implantología. Universidad de Santiago de Compostela.

Blanco Carrión A, Otero Rey E, Peñamaría Mallón M, Diniz Freitas M. Diagnóstico del liquen plano oral. Av. Odontoestomatol 2008; 24 (1): 11-31. 


\section{INTRODUCCIÓN}

El Liquen Plano (LP) es una enfermedad inflamatoria crónica, de etiología desconocida (se reconoce una base autoinmune), mucocutánea con manifestaciones orales muy frecuentes, una clínica e histología características y de curso evolutivo benigno aunque en ocasiones puede llegar a sufrir una degeneración maligna $(1,2)$.

La prevalencia del LP es desconocida. Diversos estudios la sitúan alrededor del $1 \%$ de la población total, aunque el rango varía desde el 0,1 al $4 \%$ (1). Los datos estimados para el total de la población norteamericana son de una prevalencia de $0,44 \%(3,4)$. En España los datos están entre un 0,2 y un $2 \%(2,5)$.

En cuanto a la edad de aparición, aunque puede presentarse a cualquier edad, la inmensa mayoría de los pacientes se sitúan entre la cuarta y séptima décadas de la vida, con una edad media de 50 a 55 años $(1,6)$. Puede sin embargo afectar a niños y ancianos (7-9).

Es más frecuente en las mujeres. Entre los pacientes con liquen plano oral (LPO) del $60 \%$ al $70 \%$ son mujeres (1), porcentaje que se reduce hasta el $55 \%$ en pacientes con liquen exclusivamente cutáneo (10). Diversos estudios afirman que los hombres desarrollan lesiones antes de los cuarenta años, mientras que la mayoría de las mujeres lo hacen alrededor de los cincuenta $(10,11)$.

A pesar de la mayor prevalencia entre las mujeres, no se ha encontrado ningún tipo de relación que lo justifique, es más, el cambio hormonal provocado por la menopausia no ha influido sobre la aparición del LPO o sobre el tipo clínico que desarrolle el paciente (12).

La aparición de LP no tiene una relación estacional. También se puede afirmar que no existe una predilección racial $(13,14)$.

La etiología del LP es desconocida. Se han propuesto múltiples mecanismos etiopatogénicos. Los factores posiblemente relacionados con la etiopatogenia del LP son múltiples y las formas de clasificarlos y relacionarlos también. Lo que sí está claro es que la lesión inicialmente se desarrolla en las células ba- sales del epitelio, siendo el infiltrado dérmico una manifestación secundaria. Sin embargo, todavía no ha podido ser demostrada la causa inicial que produce esta alteración en las células epiteliales. Se han enunciado diversas teorías pero ninguna de ellas ha podido ser probada.

En primer lugar, existe una predisposición genética. La presencia de diferentes antígenos de histocompatibilidad (HLA) y la afectación de varios miembros de una misma familia así lo confirma (15-17).

No se trata de un proceso infeccioso, aunque en algunas ocasiones pueda existir una sobreinfección de las lesiones $(18,19)$.

Consideramos fundamental la influencia psicosomática. La existencia de problemas emocionales, estrés, ansiedad, depresión, etc., es responsable en la mayoría de las situaciones de desencadenar la enfermedad, así como de muchas recidivas $(1,20)$.

Se asocia con diferentes enfermedades sistémicas que hacen al paciente más susceptible de padecer LP por las propias alteraciones que conlleva esa enfermedad (diabetes) o bien, procesos inmunológicamente muy similares al LP (misma base autoinmune), fundamentalmente hepatopatías crónicas y otras como miastenia gravis, lupus eritematoso, colitis ulcerosa o timoma. También se asocia con ciertas alteraciones bioquímico-enzimáticas, fundamentalmente con un aumento de colesterol (12).

El LP es un proceso autoinmune, que se demuestra sobre todo por los hallazgos histopatológicos e inmunohistoquímicos a nivel local (linfocitos T, células de Langerhans, inmunoglobulinas, complemento, etc.) $(21,22)$.

Existen unos factores que van a modificar el tiempo de evolución de la enfermedad, la capacidad de recuperación de las mucosas afectadas y también la efectividad terapéutica de los medicamentos empleados. Nos referimos a la sobreinfección bacteriana, vírica o micótica, la existencia de irritantes como el tabaco, la presencia de placa bacteriana, sobre todo en casos de localización gingival (gingivitis descamativa crónica) o la acción traumática continuada de diferentes irritantes mecánicos (12). 
Por último, hay que diferenciar las denominadas reacciones liquenoides, procesos clínica e histológicamente iguales al LP pero secundarios a un factor reconocido como fármacos, materiales odontológicos o materiales de revelado fotográfico y las lesiones liquenoides que aparecen en la reacción injerto contra huésped (23).

El diagnóstico del LPO se obtiene en primer lugar por el aspecto clínico de las lesiones. Se debe realizar siempre biopsia y estudio anatomopatológico para confirmar la sospecha clínica y realizar diagnóstico diferencial con otras entidades de apariencia clínica similar $(24,25)$.

Los pasos que debemos seguir para realizar un diagnóstico de certeza son: estudio de la clínica (anamnesis y exploración clínica), biopsia para estudio histopatológico y analítica sanguínea y determinación de la tensión arterial, buscando una posible relación con determinados procesos sistémicos. Se hará una inmunofluorescencia directa cuando haya que diferenciarlo de dermatopatías similares (lupus, penfigoide o pénfigo). En ocasiones podremos realizar un análisis estructural y otras pruebas diagnósticas.

\section{HISTORIA CLÍNICA. ANAMNESIS}

Es imprescindible realizar una buena historia clínica prestando gran atención a la anamnesis. Durante el interrogatorio al paciente debemos obtener datos sobre los siguientes parámetros:

- Antecedentes familiares: Indagaremos sobre la presencia en la familia de algún miembro con la misma enfermedad, ya que la predisposición genética se considera un elemento implicado en la etiopatogenia del LPO (15-17).

- Antecedentes personales del paciente: Debemos averiguar si el paciente está tomando algún tipo de medicación o si padece alguna enfermedad general que pueda influir en el curso de la enfermedad (diabetes) o enfermedades con la misma base inmunológica (hepatopatías crónicas, lupus, colitis ulcerosa, síndrome de Sjögren, etc.). Recordemos además que las lesiones pueden ser simples reacciones liquenoides debidas a los fármacos prescritos para el tratamiento de estas entidades clínicas. Así mismo podemos obtener datos sobre las características psicológicas de nuestro paciente y los efectos secundarios de los posibles psicofármacos $(12,26)$.

- Historia natural de las lesiones: desde cuándo tiene lesiones, el LPO es una enfermedad crónica. Es frecuente observar remisiones espontáneas, exacerbaciones y cambios en la forma y lugar de presentación. Debemos interrogar al paciente respecto a todos los posibles cambios que haya detectado, así como la respuesta ante posibles tratamientos anteriores (27).

- Sintomatología: Aunque las formas blancas del LP suelen ser asintomáticas, las formas rojas suelen cursar con dolor, incapacidad funcional, quemazón y sangrado espontáneo o al cepillado (28).

- Presencia de otras manifestaciones: Siempre hay que indagar sobre otras posibles localizaciones extraorales, cutáneas o mucosas, y de esta manera tener un diagnóstico integral del paciente (28).

\section{EXPLORACIÓN CLÍNICA}

El LP es una enfermedad mucocutánea y como tal se puede manifestar en piel, cuero cabelludo, uñas y mucosas. Puede darse cualquier combinación de éstas e incluso se ha descrito a nivel de un quiste epidermoide (29). Las manifestaciones orales son las más frecuentes, ya sea de forma única o acompañando a otras localizaciones. De hecho, un porcentaje mayoritario de los pacientes con lesiones cutáneas de liquen tienen lesiones asociadas a nivel de la cavidad oral (30), y muchos casos se inician como liquen oral y sólo alrededor del $20 \%$ acaban presentando formas clínicas en otras localizaciones $(31,32)$.

Para estudiar la clínica del LP la dividiremos en: manifestaciones orales (formas clínicas, localización y sintomatología), manifestaciones cutáneas y en otras mucosas.

\section{MANIFESTACIONES ORALES}

La cavidad oral es la principal localización y en muchas ocasiones la primera y/o única forma de presentación (5). Las lesiones de LPO se caracterizan por la gran variedad de aspectos clínicos que pue- 
den presentar. Se han propuesto multitud de clasificaciones.

\section{Formas clínicas}

Una de las primeras y que gozó de mayor popularidad es la propuesta por Andreasen (33) en la que se consideran seis formas clínicas: papular, reticular, en placas, atrófica, erosiva y ampollar.

- Papular: consistente en pequeñas elevaciones de $1 \mathrm{~mm}$, que aparecen como elementos solitarios o confluyendo en forma de lesiones más extensas (34). Se ha considerado que representa una forma aguda. (35).

- Reticular: presenta unas líneas blanquecinas que no se desprenden con el raspado (estrías de Wickham), ligeramente elevadas dispuestas de forma arboriforme o estrellada que se entremezclan dando lugar a un entramado reticular de fondo normal o eritematoso. Suele localizarse en mejillas y vestíbulo, y constituye la forma de aparición más común de la enfermedad (34). En la mucosa bucal las lesiones suelen ser bilaterales y guardan cierta simetría. Generalmente esta forma es asintomática y de descubrimiento casual (36). Son las más frecuentes, y es habitual que se asocien con otros tipos clínicos (erosivo o atrófico). Las estrías de Wickham son el signo clínico fundamental para el diagnóstico de LP (Figura 1).

- Atrófica: se presenta como un área rosácea, eritematosa, debida al adelgazamiento del epitelio que transparenta los pequeños vasos sanguíneos de las zonas inflamadas. Al igual que la eritroplasia presenta áreas eritematosas e inflamatorias por lo que se hace necesario el diagnóstico diferencial (35). Se localiza fundamentalmente en la lengua en forma de depapilaciones, en la mucosa yugal y en la encía. Cuando se sitúa a nivel gingival recibe el nombre de gingivitis descamativa crónica (37-39), afectando a la totalidad de la encía tanto por vestibular como palatino o lingual. Se acompaña de sintomatología más o menos intensa, desde una pequeña sensación urente a auténtico dolor (Figura 2).

- Ulcerativa o erosiva: se producen soluciones de continuidad en la mucosa, dando lugar a úlceras crónicas, únicas o múltiples y de características clínicas de benignidad. Se considera que se originan por trauma sobre la forma atrófica debido a la gran fragilidad del epitelio. Con mucha frecuencia presentan lesiones reticulares en la periferia (34). Se pueden localizar en cualquier zona de la cavidad oral, pero especialmente en la mucosa yugal y en la lengua. También en la encía, mucosa labial y paladar. El paciente en esta situación tiene una sintomatología manifiesta con dolor, a veces intenso, y una gran incapacidad funcional (6) (Figura 3). Dentro de esta forma de aparición, Tyldesley (40) diferencia dos tipos:

a) Erosivo menor: constituye el $65 \%$ de las lesiones. Se caracteriza por ser poco profundo y presentarse asociado a formas reticulares.

b) Erosivo mayor: afecta al $7 \%$ de los enfermos que en general son los de mayor edad. Su

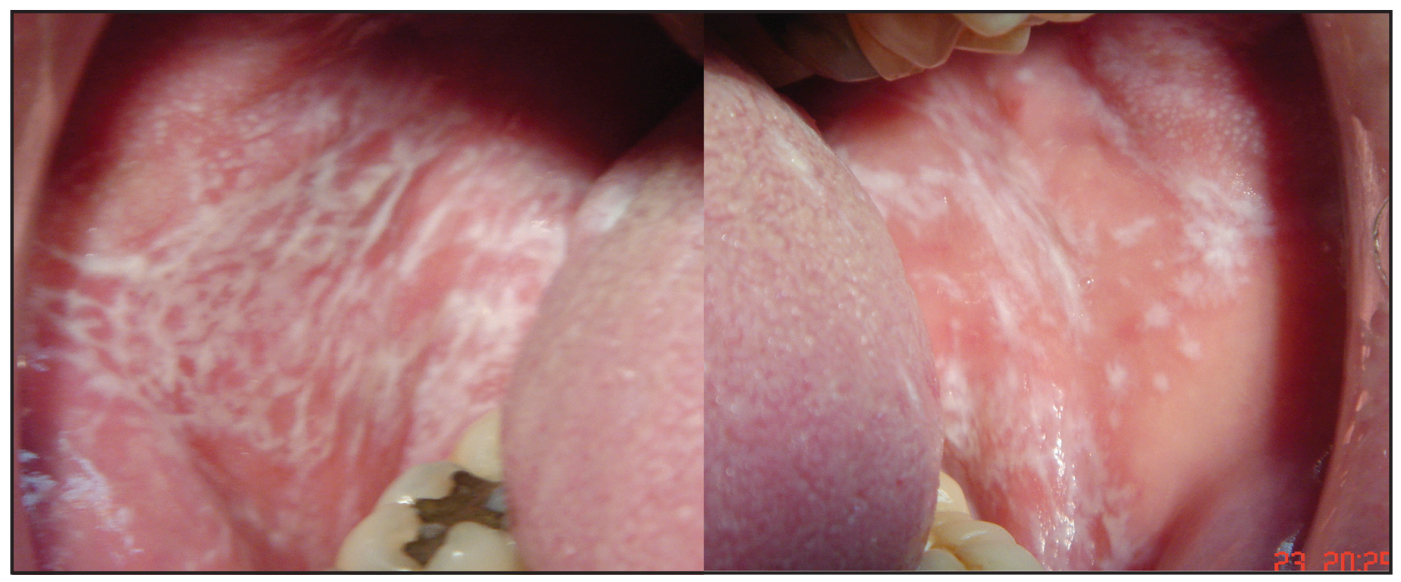

Fig.1. Imagen de un paciente con liquen plano blanco, reticular, localizado en ambas mucosas yugales, zona posterior, bilateral y simétrico. Son las estrías de Wickham muy características en el liquen plano. 


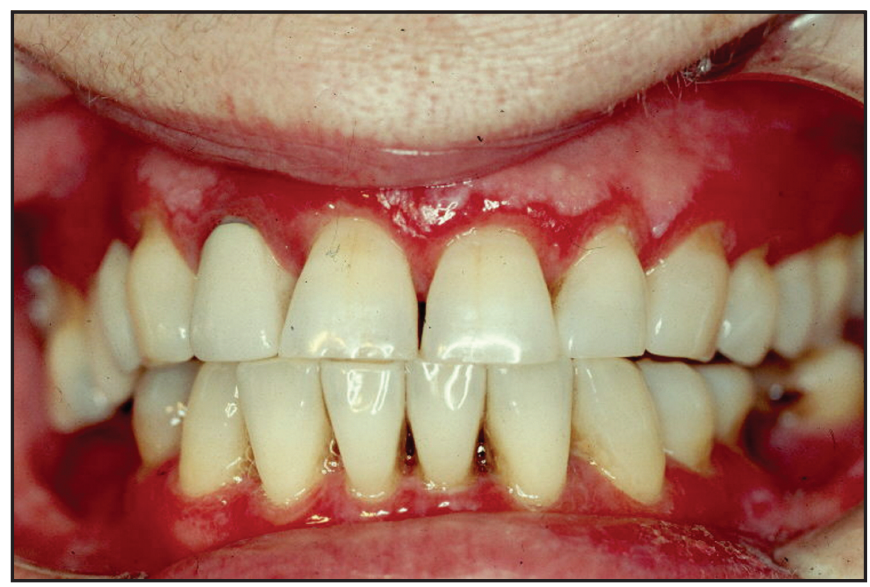

Fig.2. Lesiones en encía de liquen plano en forma de gingivitis crónica descamativa. Para el diagnóstico es recomendable hacer un estudio de inmunofluorescencia directa y poder diferenciarlo de lesiones similares como lupus, pénfigo o penfigoide.

inicio es repentino y se expande de forma amplia por la mucosa oral. Las lesiones son extensas ulceraciones cubiertas por una placa amarilla con zonas no erosivas intercaladas. Al remitir, las úlceras evolucionan a unas lesiones blancas que posteriormente se resuelven dejando una superficie lisa.

- Ampollosa: descrita por algunos autores, es una forma de manifestación rara. Puede variar desde pequeñas vesículas a grandes ampollas, causadas por el edema del tejido conectivo y el defecto de la membrana basal. La localización típica es la mucosa vestibular adyacente a los últimos molares. Puede ser necesario el diagnóstico diferencial con pénfigo, penfigoide y dermatitis herpeti- forme $(35,36)$. Lucas Tomás (41) habla de la asociación de formas erosivas y ampollosas denominándolas liquen erosivo-bulloso. Se caracterizaría por la aparición de lesiones dendríticas que contienen en su interior otras de tipo bulloso. Durarían pocas horas dejando una zona ulcerada recubierta de una pseudomembrana. Son lesiones dolorosas espontáneamente y al deglutir alimentos. Alrededor de la zona úlcero-bullosa se localizarían lesiones reticuladas que en las fases de involución podrían ocupar toda la zona anteriormente ulcerada. Se localizarían en un $90 \%$ de los casos en la mucosa yugal. Debido a la cronicidad de la lesión, su carácter recidivante y la alteración de la submucosa se le debería considerar como una lesión precancerosa.

- En placa: forma más infrecuente, similar a leucoplasia, (por lo que se hace necesario el diagnóstico diferencial con ella), se presenta como lesiones blancas elevadas, no se desprenden con el raspado y con aspecto granuloso y textura ruda $^{206}$. Se localiza más frecuentemente en la lengua y encía, y suele ser bastante rebelde al tratamiento. Se ha sugerido que podría tratarse de una evolución de las formas reticular y atrófica ante la presencia de un factor irritativo como el tabaco (35) (Figura 4).

Otros autores como Silverman (6) simplifican estas seis formas en tres: reticular, atrófica y erosiva.

Nosotros coincidimos con el criterio de Bagán y cols. $(2,28)$, dividiendo el LPO en dos formas clínicas, liquen plano blanco, en las situaciones en las que

Fig.3. Lesiones erosivas de liquen plano rojo. En mucosas yugales de forma bilateral y simétrico. Periféricamente a las úlceras aparecen estrías de Wickham características del liquen plano.

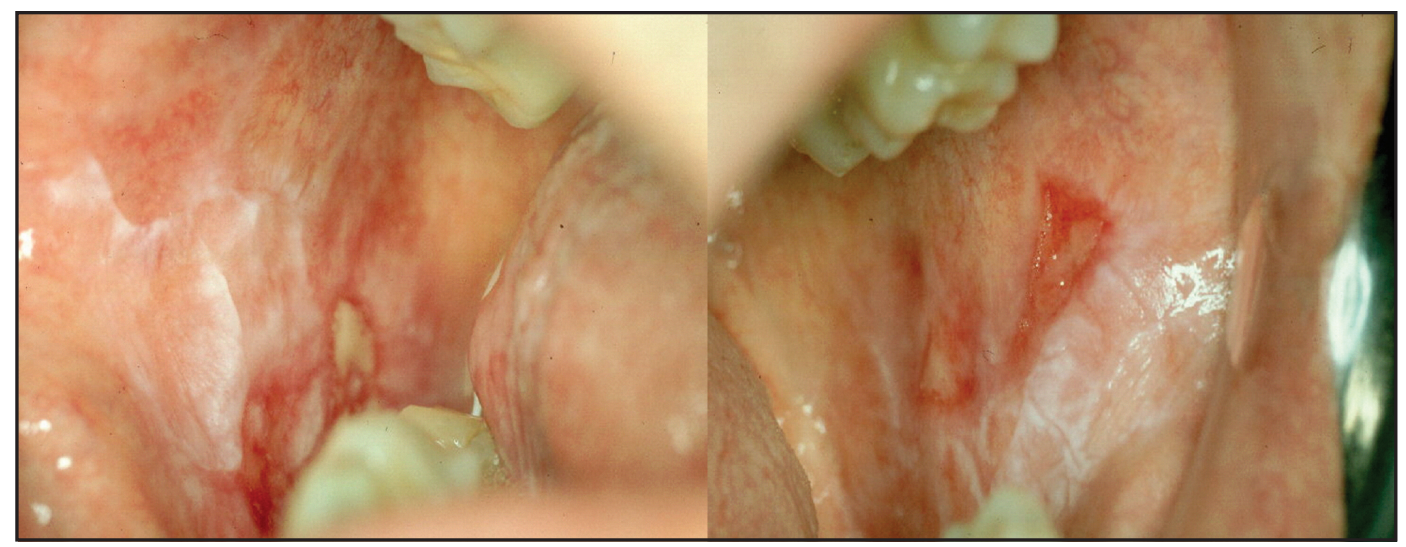




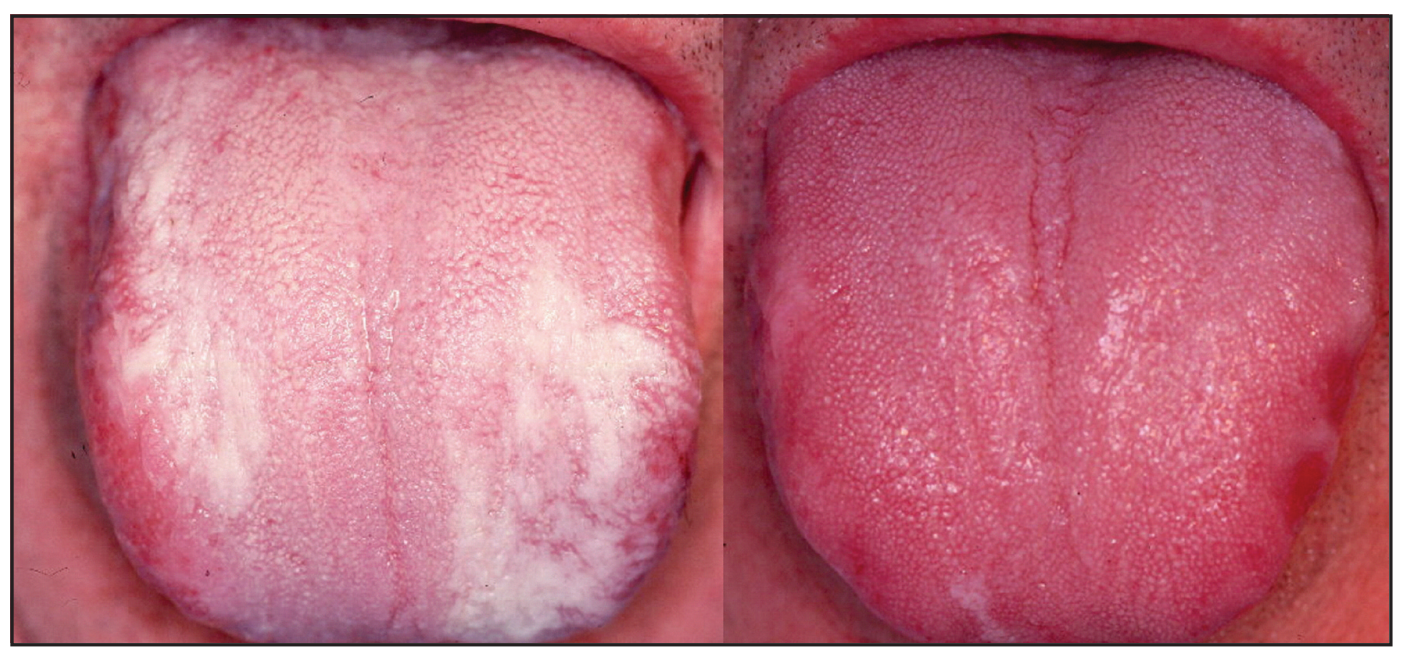

Fig.4. Liquen plano en placa en la lengua. La imagen clínica es similar a una leucoplasia. El estudio histopatológico servirá como método de diagnóstico diferencial. Las lesiones pueden llegar a desaparecer

espontáneamente, como se observa en la imagen, sin necesidad de tratamiento.

aparezcan exclusivamente formas reticulares (o en placa) y liquen plano rojo cuando aparecen formas atróficas o erosivas independientemente de que se vean formas reticulares en la periferia de éstas o en otras localizaciones. Pensamos que esta diferenciación es así de clara y ocurre desde un punto de vista práctico, clínico, evolutivo y en la aplicación del tratamiento. A partir de este momento seguiremos esta división (1).

Consideramos el resto de las formas como muy esporádicas y no estamos de acuerdo con la forma ampollosa. Las úlceras del LP son secundarias a un proceso de necrosis epitelial y no están precedidas por una ampolla como ocurre en el pénfigo, el penfigoide o eritema multiforme.

La frecuencia de aparición de una u otra forma varía según los autores. Bagán y cols. (28) en un estudio sobre doscientos pacientes encuentran un $78 \%$ de ellos con formas atrófico-erosivas y el $28 \%$ sólo reticulares. Con esto coinciden Silverman (43) por un lado y Brown (44) por otro, al estudiar grandes series de pacientes y presentar la forma erosiva como la más frecuente. Sin embargo, Thorn (45) sólo notifica un $53 \%$ de pacientes con lesiones atrófico-erosivas, y Markopoulos (46) presenta las formas reticulares como las más frecuentes. Para Eisen (47), en un estudio sobre 723 pacientes diagnosticados clínica e histológicamente de LPO, la forma erosiva era la predominante en el $40 \%$ de los casos como forma inicial de presentación. Nosotros pen- samos que es más frecuente el LP blanco pero quizás se vea menos en las consultas, sobre todo por su clínica, ya que es asintomático, suele ser un hallazgo casual y no motivo de consulta; en cambio, el LP rojo tiene una clínica importante y el paciente acude a que se le explore y demandando un tratamiento.

Las clasificaciones anteriores engloban las formas más usuales o típicas de LPO. Mencionaremos a continuación otras formas más extrañas o de aparición más atípica, descritas por algunos autores:

- Liquen zooniforme: sigue el trayecto de la tercera rama trigeminal. Se presenta de forma secundaria a la erupción del tercer molar o a una intervención quirúrgica de la zona (5).

- Liquen anular: semeja la forma de un anillo presentando una erosión en su zona central y una periferia ligeramente sobreelevada.

- Liquen Nigricans: de rara aparición en la cavidad bucal, se caracteriza por existir pigmentación melánica que enmascara las lesiones hiperqueratósicas (48).

- Liquen penfigoide: se trata de una forma más frecuente en piel que en mucosas, en la que se combinan ampollas típicas del penfigoide y otras de LP (49). No se trata de LP ampollar, en el que se presentan ampollas en zonas donde también hay lesiones reticulares, sino de la aparición en piel de lesiones ampollosas de penfigoide en pacientes con LP asociado (50-52). Existe cierta 
controversia sobre la naturaleza y entidad de esta forma clínica $(27,53)$.

Ya hemos comentado la existencia de lesiones que no cumplen todos los criterios clínicos o lesiones compatibles clínicamente con LP (25). Son las lesiones liquenoides y que responden a diferentes estímulos conocidos. Se pueden dividir en lesiones liquenoides por contacto, lesiones liquenoides medicamentosas y lesiones liquenoides de reacción injerto contra huésped (23).

\section{Localización}

El LPO puede asentar en cualquier zona de la mucosa, sin embargo, la principal localización es la mucosa yugal, en la porción posterior, y en el $90 \%$ de las ocasiones lo hace de forma bilateral y simétrica. A continuación la lengua (el dorso), y ya menos frecuentemente la encía, los labios y el paladar $(28,43,54)$.

La distribución bilateral y más o menos simétrica se considera un criterio clínico de diagnóstico de LPO. Si no es así se considera como compatible clínicamente con LPO (25).

Según las formas clínicas, en general todas siguen esta distribución. La forma de LP blanco (reticular) puede aparecer en cualquier localización, pero por orden de importancia: mucosa yugal (zona posterior, bilateral y simétrica), lengua, encía, mucosa labial y paladar. También la podemos ver en la periferia de lesiones rojas. La presentación en placas es mucho más inusual y tiene predilección por situarse en la encía y en la lengua $(28,43,54)$.

El LP rojo afecta a mucosa yugal (generalmente bilateral), lengua y encía. Menos frecuentemente a labio y paladar. Las úlceras con características clínicas de benignidad, pueden ser únicas, sobre todo en la lengua, o bien múltiples en ambas mucosas yugales de forma bilateral y colocadas en la porción posterior. En otras ocasiones aparecen múltiples úlceras en diferentes localizaciones $(28,43,54)$. El paladar no es una localización frecuente a diferencia de otras enfermedades similares como pénfigo o penfigoide benigno. Pueden presentar un aspecto cambiante a lo largo de su evolución. Consideramos que hay diversos factores que influyen en este aspecto o incluso que persisten a pesar del tratamiento o recidiven como son, irritantes mecánicos con una acción traumática continuada, sobreinfecciones o eficacia o ineficacia de las medidas terapéuticas.

Hay que hacer una mención especial a la forma atrófica. Puede aparecer en mucosa yugal, generalmente bilateral y en porción posterior, en lengua (depapilaciones) y en encía. En esta última posición recibe el nombre de gingivitis descamativa crónica. No se trata de una afección diferente sino que es una localización de una dermatopatía, en este caso LP. En otras ocasiones puede tratarse de un penfigoide benigno de mucosas, un pénfigo o un lupus eritematoso $(45,54)$.

La afectación gingival varía mucho de unos estudios a otros, siendo entre un $30 \%$ y un $50 \%(55,56)$ tanto de formas blancas $(42,7 \%)$, mixtas $(31,7 \%)$, como rojas $(25,6 \%)$ de LPO (56). La encía como única localización aparece entre un $7,4 \%$ y un $8,6 \%$. $(47,55)$.

\section{Sintomatología}

Varía totalmente según el tipo clínico. En las formas de liquen blanco se trata de lesiones totalmente asintomáticas, de hecho suelen ser un hallazgo casual y no es motivo de consulta. El paciente nota, a lo sumo, una sensación de aspereza o rugosidad en las zonas donde hay estrías $(2,28,54)$.

Otra cosa diferente es el LP rojo. La sintomatología suele ser muy evidente y va desde una sensación urente a dolor intenso que se exacerba con el roce. Los pacientes relatan una sensación de inflamación, sobre todo cuando se localizan en mucosas yugales (edema geniano). Todo ello conlleva a una incapacidad funcional, a veces importante. En ocasiones podemos encontrarnos con xerostomía, sobre todo en los casos de ingesta abundante de psicofármacos, halitosis y sobreinfección bacteriana de las erosiones con presencia de adenopatías submaxilares. La candidiasis sobreañadida puede presentarse a lo largo de la enfermedad, y sobre todo cuando tratamos al paciente con corticoides tópicos o sistémicos du- 
rante un tiempo prolongado. Todo este cuadro ha de tenerse en cuenta en el momento del tratamiento $(28,43,54)$.

En los casos de gingivitis descamativa la principal manifestación clínica es una gingivorragia, con molestias o dolor a nivel de la encía que dificulta el cepillado. Se acompaña de sensibilidad dentinaria y retracción gingival con acúmulo de placa bacteriana y cálculo.

\section{LIQUEN PLANO CUTÁNEO}

Las lesiones en la piel consisten en pápulas de entre 2 y $4 \mathrm{~mm}$ de diámetro, de forma poligonal y que aparecen de forma aislada o bien tienden a agruparse formando placas bien diferenciadas de la piel que las rodea. Inicialmente presentan color rosado que más adelante varía pasando al rojo violáceo y después a color pardo. En su superficie se pueden observar estrías blanquecinas (estrías de Wickham). Al desaparecer pueden dejar como secuela pigmentaciones melánicas. Clínicamente suelen ser pruriginosas (80\%) o bien ser asintomáticas (20\%). Afectan a cualquier parte del organismo o están delimitadas a una determinada zona. Las localizaciones frecuentes son en áreas flexoras, siendo la cara anterior de la muñeca la situación más típica. A continuación los brazos, las piernas, espalda (región lumbar), área inframamaria, zonas perigenitales y cuello. Se han descrito en otras zonas como axilas y afectaciones exclusivamente unilaterales $(3,57)$.

Las lesiones de las uñas se presentan habitualmente solo en alguna de las manos y/o de los pies. No suelen aparecer sin ir acompañadas de otras lesiones en piel o mucosa bucal. El aspecto habitual es de agrietamiento y adelgazamiento de las uñas, pudiendo llegar a su pérdida y posterior ausencia (58). A este tipo de uñas se le ha denominado "uñas en papel de fumar".

Algunos pacientes tienen afectación del cuero cabelludo, presentan una alopecia cicatricial, lo que se conoce como Síndrome de Graham-Little.

La tendencia natural del LP cutáneo es la remisión y resolución en el $90 \%$ de los individuos en un periodo de 2 a 10 años, con un porcentaje de recidiva del $20 \%(59,60)$.

\section{LIQUEN PLANO DE MUCOSAS EXTRAORALES}

Aparte de la mucosa bucal se han descrito lesiones en otras mucosas: esófago, conjuntiva, nariz, laringe, estómago, ano, vulva y pene (61-63). Puede existir una afectación plurimucosa que se conoce como síndrome vulvo-vaginal-gingival $(2,64,65)$. Se caracteriza por erosiones y descamaciones de la vulva, vagina y encías $(66,67)$.

En el estudio de Eisen (66), el 19\% de 399 mujeres con LPO tenían lesiones genitales y el 4,6\% de 174 hombres examinados. Encuentran afectación del esófago en 6 de 504 pacientes y 1 con lesión conjuntival.

En los últimos años se han publicado trabajos que muestran un incremento importante de afectación vulvovaginal en mujeres con LPO. Estos trabajos recomiendan exploraciones sistemáticas de los genitales de mujeres afectas de LPO incluso aunque no presentan sintomatología $(68,69)$.

\section{HISTOPATOLOGÍA}

La mayoría de los autores coinciden en que la biopsia es imprescindible en todos los casos de LPO, ya que nos permite confirmar nuestro diagnóstico clínico y realizar diagnóstico diferencial con otras dermatosis morfológicamente parecidas (70). Onofre y cols. (71) al estudiar diagnósticos clínicos e histológicos de una serie de lesiones potencialmente cancerosas, encuentran que existen discrepancias en aproximadamente una cuarta parte de los casos, lo que enfatiza la importancia de los análisis microscópicos. La confirmación histológica de LPO ha de incluir el diagnóstico clínico e histológico (25) (Figura 5).

De todas formas, los hallazgos histopatológicos son compatibles con el diagnóstico clínico y nunca serán patognomónicas de LPO ya que podemos ver imágenes similares en otras enfermedades similares como lupus. 


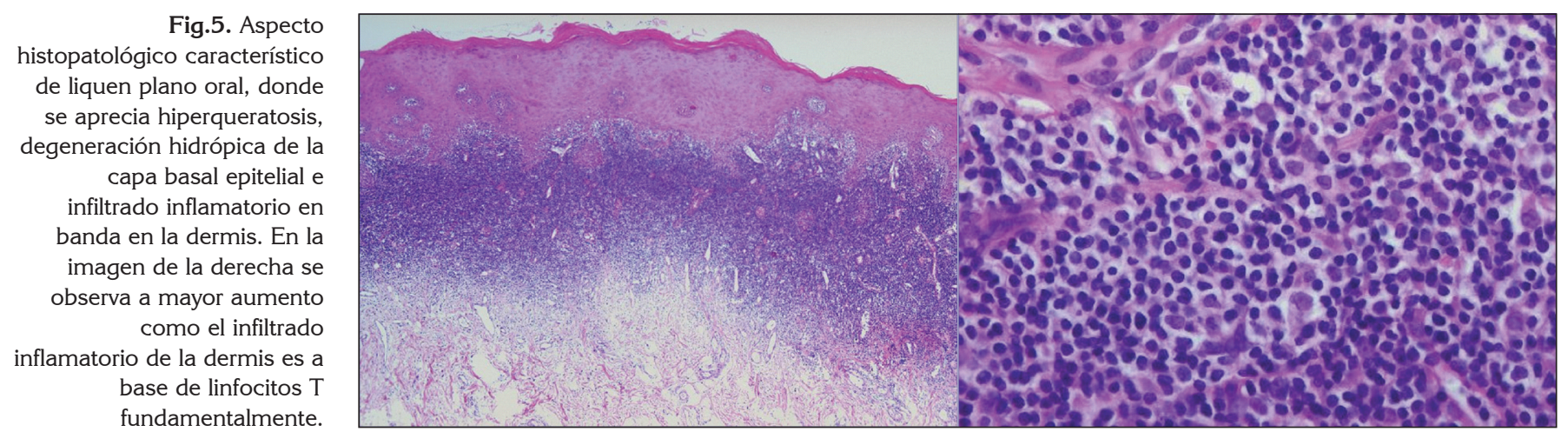

Otro dato importante a tener en cuenta es dónde hay que realizar la biopsia. No olvidemos que las alteraciones se producen fundamentalmente a nivel epitelial por lo que la biopsia hay que hacerla donde está la mucosa íntegra. Si la tomamos de una lesión ulcerada, debemos extendernos siempre hasta una zona de mucosa sana.

Utilizaremos el instrumental convencional con bisturí, tijera o punch. Se ha postulado que la utilización de la pinza $\mathrm{B}$ favorece la toma de biopsia, mejora la visibilidad, reduce la hemorragia y el tiempo de intervención y disminuye la cantidad de artefactos en la observación histopatológica (72).

Si lo que queremos es un estudio histopatológico normal, conviene fijar la muestra obtenida (formol al $10 \%)$ para su conservación. En caso de inmunofluorescencia o análisis ultraestructural, la muestra ha de llegar al patólogo en fresco para evitar la alteración proteica. En esta situación la rapidez de transporte es fundamental, considerando una hora como el plazo máximo desde la toma de biopsia hasta que llegue al servicio de anatomía patológica.

Las características principales del diagnóstico histopatológico del LP son las siguientes:

\section{a) Hiperqueratosis y acantosis}

El estrato córneo en el LP, muestra engrosamiento con ortoqueratosis, siendo la paraqueratosis inusual. Andreassen (73) señala que en el LPO esto no es cierto, puesto que la paraqueratosis está presente en el $86 \%$ de los casos. La capa de células granulares se encuentra aumentada de tamaño, con aspecto globular. Suele presentarse acantosis irregular con las papilas en patrón de dientes de sierra.

Las estrías de Wickham o líneas blancas reticulares que se aprecian en la mayoría de pacientes de LP, parecen corresponderse a nivel microscópico con un aumento de la capa granular (74). Se ha sugerido que las lesiones atróficas podrían deberse a la reabsorción de los capilares de la dermis (74), aunque otros estudios no han encontrado diferencias ni cuantitativas ni cualitativas en ellos (75). Bagán y cols. (76), al realizar un estudio de los grosores del epitelio y de la longitud media de las papilas, encuentran que ambas medidas son diferentes significativamente en las formas reticulares de las erosivas.

\section{b) Degeneración hidrópica de la capa basal}

La membrana basal es la zona histológica más significativa en el LP, estando íntimamente relacionada con la patogénesis y expresión de la enfermedad. De hecho los estudios de Sarkany y Gaylarde (77) demuestran que la lesión inicial en el LP se produce a este nivel, y que todos los otros hallazgos son secundarios. Los primeros cambios que suceden en ella son los depósitos tempranos de fibrina y en la mayoría de los casos duplicación de la capa basal. A continuación aparecen separaciones o gaps basilares entre los queratinocitos $(78,79)$. Se considera también que el inicio de la formación de cuerpos coloides es uno de los primeros cambios patológicos de la enfermedad. 
Como la membrana basal se vacuoliza, se acumulan líquidos y todo esto puede llevar a la formación de hendiduras, grietas o "ampollas" subepiteliales conocidas como espacios de Max Joseph, que se pueden apreciar en el $17 \%$ de los cortes histológicos (80).

Las células de Langerhans y los melanocitos presentan una apariencia normal (81), aunque a menudo su número se encuentra elevado $(82,83)$. Ocasionalmente se pueden localizar histiocitos (macrófagos) y linfocitos dentro de la epidermis.

Los cuerpos de Civatte, también denominados cuerpos hialinos, cuerpos coloides o cuerpos citoides, representan queratinocitos basales que han sufrido necrosis prematura debido a la degeneración hidrópica de las células basales $(84,85)$. Se localizan en zonas próximas a la capa basal o áreas profundas del estrato espinoso. Fueron descritos inicialmente por Goltz y Hult en 1963 (2). Los cuerpos coloides se han identificado en el $27 \%$ de las muestras de pacientes con LPO y hasta en el $100 \%$ de algunas series de biopsias cutáneas $(80,83,86)$.

Conforme va avanzando la enfermedad se produce una pérdida constante de tonofilamentos, desmosomas y hemidesmosomas. La desaparición de estos últimos en la capa basal explica la formación de espacios como ampollas subepiteliales (78).

Se ha intentado relacionar el grado de degeneración hidrópica de la capa basal con la paraqueratinización epitelial y con el infiltrado inflamatorio. Sin embargo no se han conseguido resultados estadísticamente significativos (87).

\section{c) Infiltrado inflamatorio en banda}

La característica histopatológica más significativa del LP es el infiltrado inflamatorio en banda a nivel de la dermis (infiltrado liquenoide). Abraza la lámina basal y sigue en disposición paralela al epitelio. Está compuesto principalmente por linfocitos $\mathrm{T}$ y macrófagos. Se ha descrito también la presencia de células plasmáticas y melanocitos $(79,80)$.

Los estudios de Bagán y cols. (76) han delimitado la profundidad media del infiltrado en $342 \mathrm{~m} \mu$, sin dife- rencias de grosor entre las lesiones atrófico-erosivas y las reticulares. Tampoco pudieron demostrar en su muestra que existiese relación entre la profundidad del infiltrado y la extensión de las lesiones en la superficie de la mucosa.

Se ha insistido mucho en el estudio de las estirpes linfocitarias presentes en el infiltrado inflamatorio del LP. Los diversos estudios indican que la gran mayoría son linfocitos $\mathrm{T}$, con muy poca presencia de linfocitos B. Dentro de la serie $\mathrm{T}$, aparecen en mayor número los colaboradores que los supresores. Esta distribución de las subpoblaciones, se verifica tanto en el tejido conectivo como en el epitelio $(80,88,89)$. No se ha podido relacionar la cantidad de linfocitos T con el tipo clínico ni con la extensión de las lesiones (90). Se ha postulado, sin embargo, que el que una lesión de LP sea reticular o atrófico-erosiva depende de los subtipos de linfocitos presentes en el infiltrado inflamatorio (de la proporción de linfocitos $\mathrm{T}$ colaboradores con respecto a las otras subpoblaciones de células T) (91).

Se ha intentado también determinar las diferencias entre lesiones activas e inactivas de LP. Akasu y cols. (92) observan en las lesiones inactivas pocas células de Langerhans y escasa infiltración de células T. En las lesiones activas aparecen gran cantidad de células positivas para el marcador CD3 en la unión dermoepidérmica y en la dermis, siendo en un $40 \%$ del tipo colaborador en la unión y alrededor del $80 \%$ en la dermis.

Se han detectado igualmente gran cantidad de células de Langerhans, macrófagos expresando lisozimas y células dendríticas positivas para el marcaje FXIla en el epitelio y en el corion (92). Estas células actuarían como presentadoras del antígeno a los linfocitos para que éstos produzcan lisis celular. Se ha demostrado que existe una relación directa entre el número de linfocitos $\mathrm{T}$ y el de células de Langerhans intraepiteliales $(83,91)$. El fenotipo de las células de Langerhans en lesiones de LP se relaciona con niveles altos de antígenos de histocompatibilidad del tipo HLA-DR, CDIa, MHC-II, y antígenos CD4 (93). Así mismo se ha sugerido que la presencia de células de Langerhans puede contribuir al diagnóstico diferencial entre LP y leucoplasia, puesto que en esta última entidad se encuentran en menor número que en el LP (94). 


\section{ANALÍTICA SANGUIINEA}

Patogénicamente el LPO se ha relacionado con enfermedades sistémicas, algunas de ellas con la misma base autoinmune. Se ha comprobado, que en su progresión, pueden influir en la evolución del LPO $(95,96)$.

Múltiples estudios han demostrado una respuesta anormal de estos enfermos a la administración de la glucosa $(97,98)$. Aquellos que utilizan pruebas de tolerancia a la glucosa por vía oral, los resultados anormales han variado del $12,5 \%$ al $85 \%$. Si consideramos que en la población general, entre el 12 y $14 \%$ presentan intolerancia a la glucosa, estas cifras obtenidas para pacientes con LP son altamente superiores $(99,100)$. La razón de tal incremento es desconocida. Otros autores sin embargo, no han podido encontrar esta relación $(101,102)$.

Se han realizado también estudios sobre la prevalencia de LP en pacientes con diabetes. Las cifras son muy bajas, estando entre el 0,5 y el 2,3\% (103-105).

Varios autores han descrito una elevada prevalencia de enfermedades hepáticas crónicas en pacientes con LP $(106,107)$. La cirrosis biliar y la hepatitis activa de causa desconocida son las que se han relacionado más frecuentemente. La prevalencia varía notablemente de un estudio a otro, desde el $0,1 \%$ al $35 \%$ $(108,109)$. En el trabajo de Rodríguez (54), el 15,38\% presentaba alguna hepatopatía. Otros autores, en cambio no han encontrado esta relación (110).

Los datos más recientes apuntan a que cuando el LP está asociado con una enfermedad hepática, la causa más frecuente es la infección por virus de la hepatitis C $(111,112)$. Se ha encontrado un incremento de anticuerpos circulantes anti-VHC en los pacientes con LPO en relación a un grupo control (113). Los resultados son muy diferentes según la zona donde se realice el estudio, abarcando desde el $4 \%$ (182) hasta el 38\% (115). Posiblemente existan diferencias geográficas por la diferente afectación de la población. También se ha descrito la asociación entre LPO y hepatitis B (116). Surge el interrogante de si los fármacos utilizados en la terapéutica de la hepatitis (D-Penicilamina o interferón) son los que verdaderamente pueden provocar una reacción liquenoide (117).

Se han descrito diferentes alteraciones bioquímico-enzimáticas en los pacientes con LP, como una disminución de la actividad enzimática de las cadenas respiratorias en la epidermis (118). Se ha podido comprobar una relación entre LP y un aumento en la concentración de colesterol en sangre (54).

Por todo ello consideramos conveniente realizar analíticas sanguíneas en los pacientes de LPO para descartar estas enfermedades. De esta forma, solicitaremos además del informe citológico, niveles de glucemia, enzimas hepáticos, colesterol y metabolismo lipídico.

También se ha relacionado el LPO con un aumento en la tensión arterial. Por ello deberíamos conocer su presión sanguínea (119).

\section{5, INMUNOFLUORESCENCIA}

La inmunofluorescencia es de especial importancia en el diagnóstico de las enfermedades inflamatorias de las mucosas.

\section{a) Inmunofluorescencia directa}

Diversos estudios señalan la presencia de depósitos inmunes en el LP. En el laboratorio de Dermatología de la Clínica Mayo requieren la presencia de depósitos de fibrinógeno a lo largo de la membrana basal, depósitos de una o más inmunoglobulinas, o ambos elementos para considerar un diagnóstico compatible con LP. En los controles de calidad de sus diagnósticos, encuentran que la presencia de fibrinógeno en la membrana basal es el mejor indicador aislado, con una sensibilidad del $70 \%$ y una especificidad del $78 \%$. Con respecto a los depósitos de inmunoglobulinas, los que poseen mayor sensibilidad son los de IgM, siendo tanto estos depósitos como los de IgG, tremendamente específicos. La combinación con mayor calidad diagnóstica (sensibilidad / especificidad) es la formada por depósitos de fibrinógeno y de IgM (120). 
Los estudios de Bagán y cols. (121) demuestran la presencia de fibrinógeno a nivel de la membrana basal en el $85 \%$ de los pacientes estudiados, en la dermis subepitelial en el $65 \%$, y en los cuerpos coloides en un $15 \%$. De todos modos la presencia de estos depósitos no puede ser considerado como un dato específico en el diagnóstico del LP, porque se han detectado en otras afecciones como en el lupus eritematoso discoide y sistémico.

Los depósitos de fibrinógeno son interpretados como un fenómeno exudativo inespecífico relacionado con la degeneración de las células de la capa basal, pudiendo indicar en ocasiones la autoperpetuación de fenómenos inflamatorios locales $(79,122)$.

La presencia de factores del complemento ha generado resultados contradictorios y no concluyentes. Schiodt (123) afirma que el $33 \%$ de su serie de 45 pacientes con LPO, presentan depósitos de C3 a lo largo de la membrana basal. Sin embargo, Bagán y cols. (121) no constatan la presencia de depósitos de esta fracción del complemento en ninguno de los pacientes de sus series. Baart de la Faille y cols. (79) detectaron positividad marcada para C4 y C3 a nivel de los cuerpos coloides, y en menor grado para C1q, C3b, y C5. Estos resultados no han podido ser confirmados por otros autores $(122,124,125)$.

Coincidiendo con otros autores, Bagán y cols. (121) encuentran en sus pacientes depósitos de $\operatorname{Ig} M$ e IgG por este orden de frecuencia, localizados en la membrana basal, cuerpos coloides, y alrededor del $30 \%$ de los casos a nivel de la dermis. Para Baart de la Faille y cols. (79), la IgM tiene máxima positividad a nivel de toda la membrana basal, y la IgG se localizaría preferentemente cerca de las zonas de degeneración hidrópica. Del mismo modo, afirman que existe una mayor positividad para la IgM que para la IgG en los cuerpos coloides. Al contrario que los anteriores autores, Laskaris y cols. (124) detectan depósitos de IgM e IgG en proporciones muy bajas.

La heterogenicidad de los resultados obtenidos nos indica el carácter inespecífico de los depósitos. Se explicaría la presencia de inmunoglobulinas como una reacción policlonal inespecífica secundaria a la respuesta celular mediada por los linfocitos T (126).
La encía parece ser la mejor zona para la biopsia y estudio de inmunofluorescencia directa, lo que confirma su utilidad en la investigación de la gingivitis descamativa $(127,128)$. Del mismo modo, parecen ser mucho más específicos de LP los depósitos de inmunoglobulinas a nivel de la mucosa oral, que a nivel de especímenes cutáneos (120).

Nuestra opinión es que la inmunofluorescencia directa es casi siempre negativa para el LP, utilizándola para diagnóstico diferencial con enfermedades parecidas donde sí es positiva.

\section{b) Inmunofluorescencia indirecta}

Son pocos los estudios disponibles sobre el LP con esta técnica. A priori los más interesantes serían los de Olsen y cols. $(129,130)$, que detectaron un antígeno epidérmico específico soluble del LP que serviría de marcador específico para poder distinguirlo de otras lesiones con manifestaciones clínicas y morfológicas similares. Se detectaría en el $80 \%$ de los casos y se localizaría a nivel del estrato granuloso y espinoso, pero no en la dermis, estrato basal y córneo. Como hemos dicho, Olsen y cols. $(129,130)$ no detectaron este antígeno al estudiar muestras de piel normal y de otras dermatosis con datos diagnósticos tan similares como el lupus eritematoso y las reacciones liquenoides en la enfermedad de injerto contra huésped.

Sin embargo Bagán y cols. (131) al llevar a cabo estudios similares sobre pacientes con LPO, (Olsen utilizó especímenes cutáneos), no pudieron detectar el antígeno específico epidérmico del LP.

A la vista de los resultados contradictorios de la inmunofluorescencia indirecta, Carrizosa y cols. (132) han realizado un estudio para determinar la presencia de anticuerpos antinucleares utilizando distintos substratos. Sus resultados muestran que la presencia de anticuerpos antinucleares en los pacientes con LP depende del substrato empleado, y que con el que se obtiene mayor positividad es con esófago de rata (alrededor del 40\%). También encuentran que la presencia de anticuerpos nucleares es más frecuente en pacientes con LP erosivo que en pacientes con LP reticular. 


\section{ANÁLISIS ULTRAESTRUCTURAL}

En los primeros estadios de la enfermedad, los estudios de microscopía electrónica muestran mitocondrias normales, pero según va avanzando la enfermedad disminuye el número de crestas y aparecen signos de vacuolización (81). Clausen y cols. (78) afirman que las mitocondrias de las células basales se encuentran hinchadas, pero esto sólo indica daño celular inespecífico. El retículo endoplásmico y el aparato de Golgi no parecen verse afectados. Bagán y cols. (133) aprecian en fases más tardías degeneración balonizante mitocondrial, microvesiculación del retículo endoplásmico y disgregación de las cubiertas membranosas.

Posteriormente, empieza a apreciarse una reducción en el número y modificaciones tanto en la distribución como en la densidad de los tonofilamentos intracitoplasmáticos de los queratinocitos basales y de la capa más profunda del estrato espinoso (35).

Finalmente, puede apreciarse degeneración citoplasmática vacuolada, con aumento del espacio extracelular y desaparición de los desmosomas (28). Este proceso a nivel de las células de la capa basal produce la formación de los anteriormente mencionados cuerpos coloides. Se cree que están formados por una malla uniforme de filamentos de 70-90 Amstrongs, derivados de los tonofilamentos intracelulares, y con menor densidad electrónica que ellos. Según Bagán y cols. (131), los cuerpos coloides son producto de un fenómeno de degeneración conocido como apoptosis. Eady y cols (134) han descrito un tipo celular que, por sus características morfológicas, consideran precursor de los cuerpos coloides. Se han denominado células mitad y mitad (half-half cells), porque por una banda son ricas en orgánulos pero con pocos tonofilamentos, y por otra, tienen pocos orgánulos pero con gran cantidad de tonofilamentos. Consideran los autores que la zona con orgánulos presenta una gran actividad metabólica y de síntesis proteica, que llevaría a la formación de gran cantidad de tonofilamentos y posteriormente los cuerpos coloides. Estos hallazgos no han sido confirmados por otros autores.

Al microscopio electrónico se puede también observar que los hemidesmosomas sufren igualmente degeneración, lo que produce la separación de las células basales de la membrana basal, que termina fragmentándose. Esto da lugar a un paso de células desde la dermis al epitelio, fundamentalmente linfocitos, lo que se denomina exocitosis (linfocitosis) intraepitelial (135).

El estudio ultraestructural del infiltrado inflamatorio nos confirma que está formado principalmente por linfocitos y células de carácter histiocitario, reconocibles por la presencia de gránulos intracitoplasmáticos de origen lisosomal y cuerpos residuales. En el epitelio se observan además macrófagos y células de Langerhans. En el trabajo de Bagán y cols. (131) se demuestra que existe una unión íntima entre los linfocitos, queratinocitos y las células de Langerhans.

Hirota y Osaki (136) presentan un estudio en el que buscan diferencias ultraestructurales entre las porciones periféricas y centrales de las lesiones. En la periferia no observan signos de degeneración en los queratinocitos, aunque existe pérdida de desmosomas con ensanchamiento del espacio intercelular. Existe una pérdida parcial de los hemidesmosomas, pero no se observan células del infiltrado dérmico en el epitelio. En la porción central de las lesiones, los fragmentos degenerativos son más marcados y ya pueden observarse células del infiltrado inflamatorio en el epitelio.

A la luz de los estudios mencionados anteriormente de Sarkany y Gaylarde (77), Hirota y Osaki (136) y otros anteriores como los de Sklar (137), se demuestra que el origen de las lesiones no es mesenquimal, si no que los mecanismos patogénicos se inician en el estrato basal del epitelio y la infiltración de células inflamatorias es un fenómeno secundario. Más concretamente, los estudios ultraestructurales sugieren que los linfocitos reciben la información desde las llamadas células presentadoras de antígenos (macrófagos, células de Langerhans, y otras), y a partir de ahí, los linfocitos atacan las células epiteliales.

\section{OTRAS PRUEBAS DIAGNÓSTICAS}

Se ha sugerido la posibilidad de que la alergia al mercurio (138) sea habitual en pacientes con reacciones liquenoides orales y que es interesante la realización de test de alergia con parches epicutáneos. 
La frecuencia de resultados positivos de estos tests es variable en la literatura (138-141), pero el estudio de Skoglund (142) demuestra que desde un punto de vista clínico los test epicutáneos carecen de utilidad en la gran mayoría de los casos.

Sugerman y cols. (143) han sugerido la utilidad de las citologías exfoliativas para el diagnóstico y control de los pacientes con LPO. En sus estudios observan cambios en el tamaño del citoplasma y en la relación núcleo/citoplasmática en los frotis de pacientes con LP frente a frotis de individuos sanos. Aprecian también cambios epiteliales en mucosas clínicamente sanas de pacientes con LPO. Estos mismos resultado los encuentran Mollaoglu y cols (144) y Rode y cols (145).

En los últimos años la citometría de flujo se ha convertido en una de las técnicas de diagnóstico más interesantes y que ha alcanzado una relevancia más destacada como complemento valioso en el estudio de la morfología, bioquímica y biología celular. Aporta una gran sensibilidad, objetividad y rapidez al analizar simultáneamente diversas características celulares, lo que nos permite conocer gran número de parámetros de cada una de las células que se analizan. De las múltiples aplicaciones de la citometría de flujo, nos interesa su capacidad para determinar antígenos situados en la membrana plasmática celular. Al combinar distintos anticuerpos monoclonales con especificidad para antígenos celulares podemos identificar poblaciones celulares específicas $(146,147)$.

La quimioluminiscencia se ha comprobado como mejor método para detectar cáncer oral y lesiones premalignas en comparación con métodos similares (148).

A través de videocapilaroscopia se podría observar la microcirculación y la angiogénesis en pacientes con LPO en comparación con pacientes sanos (149).

Se ha sugerido estudiar los cambios metabólicos en boca y saliva como medio para valorar los cambios que ocurren en el cáncer oral, lesiones premalignas y pacientes sanos (150).

En nuestra opinión y como resumen, el diagnóstico del LP debe ser clínico, mediante anamnesis y exploración clínica, confirmándose con una biopsia y es- tudio histopatológico donde ha de observarse hiperqueratosis y acantosis, degeneración hidrópica de la capa basal y sobre todo un infiltrado inflamatorio en banda. Aconsejamos la realización de una analítica sanguínea para valorar posibles alteraciones que se identifiquen con procesos patológicos relacionados.

La inmunofluorescencia directa se utilizará para aquellos casos en los que las manifestaciones clínicas no sean muy evidentes y haya que hacer diagnóstico diferencial con otras enfermedades como lupus, pénfigo o penfigoide. El resto de pruebas diagnósticas tendrán una indicación más bien académica y no tan práctica.

\section{BIBLIOGRAFÍA}

1. Blanco Carrión A. Liquen plano oral. Madrid: Ediciones Avances Médico-Dentales, SL, 2000.

2. Bagán Sebastián JV, Cerero Lapiedra R. Liquen plano oral. En: Bagán Sebastián JV, Ceballos Salobreña A, Bermejo Fenoll A, Aguirre Urizar JM, Peñarrocha Diago M. Medicina Oral. Barcelona: Masson, 1995:202-19.

3. Boyd AS, Neldner KH. Lichen planus. J Am Acad Dermatol 1991;25:593-619.

4. Bouquot JE, Gorlin RJ. Leukoplakia, lichen planus and other oral queratosis in 23.616 white americans over the age of 35 years. Oral Surg Oral Med Oral Pathol 1986;61:373-81.

5. Bascones A, Llanes F. Lesiones blancas: leucoplasia, liquen bucal y otras lesiones blancas. En: Bascones A, Llanes F. Medicina Bucal. Madrid. Ediciones Avances 1991:98-108.

6. Silverman S, Gorsky M, Lozada-Nur F. A prospective follow-up study of 570 patients with oral lichen planus: persistence, remission, and malignant asociation. Oral Surg Oral Med Oral Pathol 1985;60:30-4.

7. Vijay K, Bhagat RG, Manik CB, Srinivas SV. Childhood lichen planus. J Dermatol 1993;20: 175-7. 
8. Scully C, De Almeida OP, Welbury R. Oral lichen planus in childhood. British J Dermatol 1994; 130:131-3.

9. Laeijendecker R, van Joost T, Tank B, Oranje AP, Neumann HA. Oral lichen planus in childhood. Pediatr Dermatol 2005;22:299-304.

10. Schmidt H. Frecuency, duration and localization of lichen planus. Acta Derm Venereol (Stockh) 1961;41:164-7.

11. Irvine C, Irvine F, Champion RH. Long-term follow up of lichen planus. Acta Derm Venereol 1991;71:242-4.

12. Blanco A, Gandara JM, Rodríguez A, García A, Rodríguez I. Alteraciones bioquímicas y su correlación clínica con el liquen plano oral. Med Oral 2000;5:238-49.

13. Axell T, Rundquist L. Oral lichen planus, a demographic study. Community Dent Oral Epidemiol 1987;15:52-6.

14. Chattopadhyay A. Study of epidemiological features of oral lichen planus. Ind J Derm 1988; 33:13-15.

15. Bermejo Fenoll A, Oñate Sanchez RE, López Jornet P, Sanchez Pérez A. Liquen plano familiar: presentación de nuevos casos clínicos. Av Odontoestomatol 1993;9:41-46.

16. Kofoed ML, Wantzin GL. Familial lichen planus. J Am Acad Dermatol 1985;13:50-4.

17. Sandhu K, Handa S, Kanwar AJ. Familial lichen planus. Pediatr Dermatol 2003;20:186.

18. González-Moles MA, Rodriguez-Archilla A, Ruiz Ávila I, Esteban F, González-Moles S, Bravo M. Presence of HPV 16 sequences in oral lichen planus lesions. Bull Group Int Rech Sci Stomatol Odontol 1998;40:92-7.

19. Lepperheide V, Quindos G, Jimenez Y, Ponton J, Bagán-Sebastian JV, Aguirre JM. Candida biotypes in patients with oral leukoplakia and lichen planus. Mycopathologia 1996;134:7582.

20. Rojo-Moreno JL, Bagán JV, Rojo-Moreno J, Donat JS, Milián MA, Jimenez Y. Psychologic factors and oral lichen planus. A psychometric evaluation of 100 cases. Oral Surg Oral Med Oral Pathol Oral Radiol Endod 1998;86:687-91.

21. Rodriguez-Nuñez I, Blanco-Carrión A, García AG, Rey JG. Peripheral T-cell subsets in patients with reticular and atrophic-erosive oral lichen planus. Oral Surg Oral Med Oral Pathol Oral Radiol Endod 2001;91:180-8.

22. Gándara-Rey JM, García-García A, Blanco-Carrión A, Gándara-Vila P, Rodriguez-Nuñez I. Alteraciones de la inmunidad celular en 52 pacientes con liquen plano oral. Med Oral 2001;6:246-62.

23. Al-Hashimi I, Schifter M, Lockhart PB, Wray D, Brennan M, Migliorati CA, Axéll T, Bruce AJ, Carpenter W, Eisenberg E, Epstein JB, Holmstrup P, Jontell M, Lozada-Nur F, Nair R, Silverman B, Thongprasom K, Thornhill M, Warnakulasuriya S, van der Waal I. Oral lichen planus and oral lichenoid lesions: diagnostic and therapeutic considerations. Oral Surg Oral Med Oral Pathol Oral Radiol Endod 2007;103 (suppl):1-12.

24. Csully C, CarrozzoM. Oral mucosal disease: Lichen planus. Br J Oral Maxillofac Surg 2007 (en prensa).

25. van der Meij EH, van der Wall I. Lack of clinicopathologic correlation in the diagnosis of oral lichen planus based on the presently available diagnostic criteria and suggestions for modifications. J Oral Pathol Med 2003;32: 507-12.

26. Fantasia JE. Diagnosis and treatment of common oral lesions found in the elderly. Dent Clin North Am 1997;4:877-90.

27. Davis AL, Bhogal BS, Whitehead P. Lichen planus pemphigoides: its relationship to bullous pemphigoid. Br J Dermatol 1991;125:263-71. 
28. Bagán Sebastián JV, Milian Masanet MA, Peñarrocha Diago M, Jimenez Y. A clinical study of 205 patients with oral lichen planus. J Oral Maxillofac Surg 1992;50:116-8.

29. Bork K, Hoede N. Lichen planus: histological involvement of an epidermoid cyst. Dermatologica 1983; 166:319.

30. Shklar G, McCarthy PL. The oral lesions of lichen planus. Oral Surg 1961;14:164-81.

31. Cooke BED. The oral manifestations of lichen planus: 50 Cases. Br Dent J 1954; 96:1-9.

32. Dechaume M, Payen J, Piriou J. Le lichen plan isolé de la muqueuse bucale. Considerations anatomocliniques d'apres 50 observations dont 30 avec examen histologique. Presse Med 1957; 65:2133-5.

33. Andreasen JO. Oral lichen planus. A clinical evaluation of 115 cases. Oral Surg 1968;25:31-41.

34. Venneri P, Forabosco A, Criscuolo M, Galetti R, Santantorio R. El liquen rojo plano. Revisión de la literatura y presentación clínica de un caso. Riv Odontoestomatol Implantoprotesi 1992;5: 251-5.

35. López López J, Ferre Jorge J, Roselló Llabres X. Liquen plano oral: revisión. Av Odontoestomatol 1993;9:461-5.

36. Karen K, Batsokis JG, Kyung-Jacho. Lichen planus and lichenoid lesions of the oral cavity. Ann Otol Rhinol Laryngol 1994;33:13-5.

37. Holmstrup P, Welborg A, Westergaard J. Effect of dental plaque control on gingival lichen planus. Oral Surg Oral Med Oral Pathol 1990;69:585-90.

38. Sklavounou AD, Laskaris G. Frecuency of desquamative gingivitis in skin diseases. Oral Surg 1983;56:141-4.

39. Ziskin DE, Silvers HF. Report of a case of descuamative gingivitis and lichen planus. J Periodontol 1945;16 7-11.
40. Tyldesley WR. Lesiones orales en las enfermedades de la piel. En: Tyldesley WR. Atlas de enfermedades orofaciales. Madrid: Avances, 1992: 34-41.

41. Lucas Tomás M. Liquen Plano. En: Lucas Tomás M. Medicina Oral. Barcelona: Salvat, 1988:99100.

42. Eversole LP. Dermatosis. Liquen Plano. En: Eversole LP Patología bucal: Diagnóstico y tratamiento. La Habana: Científico-Técnica, 1983; 23-24.

43. Silverman SJr, Gorsky M, Lozada Nur F, Giannotti K. A prospective study of findings and management in 214 patients with oral lichen planus. Oral Surg 1991; 72:665-70.

44. Brown RS, Bottomley WK, Puente E, Lavigne GJ. A retrospective evaluation of 193 patients with oral lichen planus. J Oral Pathol Med 1993;22: 69-72.

45. Thorn JJ, Holmstrup P, Pindborg JJ. Course of various clinical forms of oral lichen planus. A prospective follow-up study of 611 patients. J Oral Pathol 1988;17: 213-8.

46. Makopoulus A, Kayavis A, Paleologoy A, Papanagiotu P, Trigonidis G. Oral lichen planus. A clinical study of 228 cases. Hell Stomatol Cron 1989;33:107-11.

47. Eisen D. The clinical features, malignant potential, and systemic associations of oral lichen planus: a study of 723 patients. J Am Acad Dermatol 2002; 46:207-14.

48. Dechaume, Grellet, Laudenbach. Lesiones crónicas de la mucosa oral. Queratosis: liquen plano. Estomatología 1981; 35-39.

49. Cognat T, Gayrard L, Adam C. Lichen planus pemphigoides. Ann Dermatol Venereol 1991; 118:387-90.

50. Archer CB, Cronin E, Smith NP. Diagnosis of lichen planus pemphigoides in the absence of 
bullae on normal appearing skin. Clin Exp Dermatol 1992;17:433-6.

51. Maceyko RF, Camisa C, Bergfeld WF, Valenzuela R. Oral and cutaneous lichen planus pemphigoides. J Am Acad Dermatol 1992;27: 889-92.

52. Solomon LW, Helm TN, Stevens C, Neiders ME, Kumar V. Clinical and immunopathologic findings in oral lichen planus pemphigoides. Oral Surg Oral Med Oral Pathol Oral Radiol Endod 2007;103:808-13.

53. Murphy GM, Cronin E. Lichen planus pemphigoides. Clin Exp Dermatol 1989;14:322-4.

54. Rodriguez Núñez I. Alteraciones bioquímicas e inmunológicas y su correlación clínica en el liquen plano oral. Tesis Doctoral. Universidad de Santiago de Compostela. 1999.

55. Mignogna MD, Lo Russo L, Fedele S. Gingival involvement of oral lichen planus in a series of 700 patients. J Clin Periodontol. 2005;32: 102933.

56. Camacho-Alonso F, López-Jornet P, BermejoFenoll A.Gingival involvement of oral lichen planus. J Periodontol 2007;78:640-4.

57. Scully C, El-Kom M. Lichen planus: review and update on pathogenesis. J Oral Pathol 1985; 14 : 431-58.

58. Scott MJ, Scott MJ. Ungual lichen planus. Arch Dermatol 1979;115:1197-9.

59. Samman PD. Lichen planus: an analysis of 200 cases. Trans St Johns Hosp Derm Soc 1961;46: 36.

60. Moschella SL, Pillbury DM, Hurley HJ. Dermatology. Philadelphia. Saunders Co. 1985.

61. Tydesley WR. Oral lichen planus. Br J Oral Surg 1974;11:187.

62. Lefer LG. Lichen planus of the esophagus. Am J Dermatol 1982;4:267-70.
63. Dickens CM, Heseltine D, Walton S. The esophagus in lichen planus: an endoscopic study. Br Med J 1990;84:300-3.

64. Ramer MA, Altchek A, Deligdisch L, Phelps R, Montazem A, Buonocore PM.Lichen planus and the vulvovaginal-gingival syndrome. J Periodontol 2003;74:1385-93.

65. Yoshida M, Maeyama Y, Yasumoto S, Hashimoto T. Vulvo-vaginal-gingival syndrome of lichen planus. Int J Dermatol 2006;45:1252-4.

66. Eisen D. The vulvo-vaginal syndrome of lichen planus. The clinical characteristics of 22 patients. Arch Derm 1994;130:1379-82.

67. Pelisse $M$. The vulvo-vaginal-gingival syndrome: a new form of erosive lichen planus. Int $\mathrm{J}$ Dermatol 1989;28:381-4.

68. Belfiore P, Di Fede O, Cabibi D, Campisi G, Amarù GS, De Cantis S, Maresi E. Prevalence of vulval lichen planus in a cohort of women with oral lichen planus: an interdisciplinary study. $\mathrm{Br} \mathrm{J}$ Dermatol 2006;155:994-8.

69. Di Fede O, Belfiore P, Cabibi D, De Cantis S, Maresi E, Kerr AR, Campisi G. Unexpectedly high frequency of genital involvement in women with clinical and histological features of oral lichen planus. Acta Derm Venereol 2006;86:433-8.

70. Murrah VA, Pérez LM. Oral lichen planus: parameters affecting accurate diagnosis and effective management. Pract Periodontics Aesthet Dent 1997;9:613-20.

71. Onofre MA, Sposto MR, Navarro CM, Motta ME, Turatti E, Almeida RT. Potentially malignant epithelial lesions: discrepancies between clinical and histological diagnosis. Oral Dis 1997;3:148-52.

72. Bermejo-Fenoll A, López-Jornet MP, Jiménez-Torres MJ, Camacho-Alonso F, Orduña-Domingo A. Biopsy of the buccal mucosa in oral lichen planus: the traditional method versus the use of a new pressure forceps. J Am Dent Assoc 2007; 138:957-62. 
73. Andreasen JO. Oral lichen planus II. A histologic evaluation of ninety-seven cases. Oral Surg 1968; 25:158-66.

74. Ryan TJ. Lichen planus, Wickham's striae and blood vessels. Br J Dermatol 1971;85:497-8.

75. Rivers JK, Jackson R, Orizaga M. Who was Wickham and what are his striae? Int J Dermatol 1986;25:611-3.

76. Bagán Sebastian JV, Aguirre Urizar JM, Milian Masanet A, Peñarrocha Diago M, García Pola Vallejo MJ. A morphometric study of 74 cases of oral lichen planus. Rev Stomatol Chir Maxillofac 1991;92:265-8.

77. Sarkany I, Gaylarde PM. Ultraestructural an light microscopic changes of the epidermal-dermal juntion in lichen planus. Trans St Jhon's Hosp Derm Soc (Lond) 1971;57:139-42.

78. Clausen J, Kjaergaard J, Bierring F. Ultraestructure of the dermo-epidermal junction in lichen planus. Acta Derm Venereol (Stockh) 1981; 61:101-6.

79. Baart de la Faille-Kuyper EH, Baart de la Faille H. An immunofluorescence study of lichen planus. Br J Dermatol 1974;90:365-71.

80. Ellis FA. Hystopathology of lichen planus based on analysis of one hundred biopsy specimens. J Invest Dermatol 1967;48:143-8.

81. Johnson FR, Fry L. Ultraestructural observations on lichen planus. Arch Dermatol 1967;95:596607.

82. Conklin RJ, Blasberg B. Oral Lichen Planus. Dermatol Clin 1987;5:663-73.

83. Bhan AK, Harrist TJ, Murphy GF y cols. T cell subsets and Langerhans cells in lichen planus: in situ characterization using monoclonal antibodies. Br J Dermatol 1981;105:617-22.

84. Taaffe A. Current concepts in lichen planus. Int $\mathrm{J}$ Dermatol 1979;18:533-8.
85. Konrad K, Pehamberger H, Holubar K. Ultraestructural localization of immunoglobulin and fibrin in lichen planus. J Am Acad Dermatol 1979;1: 233-9.

86. Rogers RS, Jordon RE. Immunopathology of oral mucosal inflamatory diseases. Clin Exp Dermatol 1977;2:97-107.

87. Hedberg N, Nunter NA. A semi-quantitative assesment of the histopathology of oral lichen planus. J Oral Pathol 1986;15:268-72.

88. Bjerke JR. Subpoblations of mononuclear cells in lesions of psoriasis, lichen planus and discoid lupus erytyhematosus studied using monoclonal antibodies. Acta Derm Venereol (Stockh) 1982; 62:477-83.

89. Becker J, Loning TH, Reichart P y cols. Oral lichen planus: characterization of immunocompetent cells with hybridoma antibodies. Oral Pathol 1980;12:117-23.

90. Matthews JB, Scully CM, Potts AJC. Oral lichen planus: an immunoperoxidase study using monoclonal antibodies to lymphocyte subsets. $\mathrm{Br} \mathrm{J}$ Dermatol 1984;111:587-95.

91. Bagán Sebastian JV, Peydró Olaya A, Millán Massanet MA. Estudio inmunohistoquímico en 55 casos de liquen plano oral. Av Odontoestomatol 1992;8:75-80.

92. Akasu R, From L, Kahn HJ. Lymphocyte and macrophage subsets in active and inactive lesions of lichen planus. Am J Dermatophatol 1993;15: 217-23.

93. Walsh LJ, Savage W, Ishii T, Seymour GJ. Immunopathogenesis of oral lichen planus. J Oral Pathol Med 1990;19:389-96.

94. Rich AM, Reade PC. A cuantitative assesment of Langerhans cells in oral mucosal lichen planus and leukoplakia. Br J Dermatol 1989;120:223-8.

95. Bagán Sebastián JV, Jiménez Soriano Y, Milián Masanet MA. Liquen plano oral. En: Bermejo Fenoll A. Medicina Bucal Vol I. Madrid: Síntesis, 1998:194-202. 
96. Romero MA, Seoane J, Varela-Centelles P, DizDios P, Otero XL. Clinical and pathological characteristics of oral lichen planus in hepatitis C-positive and -negative patients. Clin Otolaryngol Allied Sci 2002;27:22-6.

97. Romero MA, Seoane J, Varela-Centelles P, DizDios P, Garcia-Pola MJ. Prevalence of diabetes mellitus amongst oral lichen planus patients. Clinical and pathological characteristics. Med Oral 2002;7:121-9.

98. Seyhan M, Ozcan H, Sahin I, Bayram N, Karincaoğlu Y. High prevalence of glucose metabolism disturbance in patients with lichen planus. Diabetes Res Clin Pract 2007;77:198202.

99. Halevy S, Feuerman EJ. Abnormal glucose tolerance associated with lichen planus. Acta Derm Venereol(Stockh) 1979;59:167-70.

100. Lundström IMC. Incidence of diabetes mellitus in patients with oral lichen planus. Int $\mathrm{J}$ Oral Surg 1983;12:147-52.

101. Christensen E, Holmstrup P, Wiberg-Jorgensen F. Glucose tolerance in patients with oral lichen planus. J Oral Pathol 1977;6:143-51.

102. Lozada-Nur F, Luangjarmekorn L, Silverman S. Assestment of plasma glucose in 99 patients with oral lichen planus. J Oral Med 1985;40: 60-1.

103. Bagán JV, Gistbert C, Milian A. Patología de la mucosa oral en el paciente diabético I. Estudio de 44 casos. Med Cut ILA 1988;16:41921.

104. Albrech M, Banocy J, Dinya E, Tamas G. Occurence of oral leukoplakia and lichen planus in diabetes mellitus. J Oral Pathol Med 1992; 21:364-6.

105. Borghelli RF, Pettinari IL, Chuchurru JA, Stirparo MA. Oral lichen planus in patients with diabetes. An epidemiologic study. Oral Surg Oral Med Oral Pathol 1993;75:498-500.
106. Rebora A, Rongioletti F. Lichen planus and chronic active hepatitis. Acta Derm Venereol (Stockh) 1984;64:52-6.

107. Ayala F, Balato N, Tranfaglia A, Guadagnino V, Orlando R. Oral erosive lichen planus and chronic liver disease. J Am Acad Dermatol 1986;14:139-40.

108. Korkij W, Chuang TY, Soltani K. Liver anormalities in patients with lichen planus: a retrospective case-control study. J Am Acad Dermatol 1984;11:609-15.

109. Bagán JV, Aguirre JM, del Olmo JA, Milián A, Peñarrocha M, Rodrigo JM, Cardona F. Oral lichen planus and chronic liver disease: a clinical and morphometric study of the oral lesions in relation to transaminase elevation. Oral Surg Oral Med Oral Pathol 1994;78: 337-42.

110. Friedrich RE, Heiland M, El-Moawen A, Dogan A, von Schrenck T, Löning T. Oral lichen planus in patients with chronic liver diseases. Infection 2003;31:383-6.

111. Mignogna MD, Lo Muzio L, Favia G, Mignogna RE, Carbone R, Bucci E. Oral lichen planus and HCV infection: a clinical evaluation of 263 cases. Int J Dermatol 1998;37:575-8.

112. Bagán JV, Ramón C, González L, Diago M, Milián MA, Cors R, Lloria E, Cardona F, Jimenez Y. Preliminary investigation of the association of oral lichen planus and hepatitis C. Oral Surg Oral Med Oral Pathol Oral Radiol Endod 1998; 85:532-6.

113. Lodi G, Giuliani M, Majorana A, Sardella A, Bez C, Demarosi F, Carrassi A. Lichen planus and hepatitis $C$ virus: a multicentre study of patients with oral lesions and a systematic review. $\mathrm{Br} \mathrm{J}$ Dermatol 2004;151:1172-81.

114. Cribier B, Gamier C, Laustriat D, Heild E. Lichen planus and hepatitis $C$ virus infection: an epidemiologic study. J Am Acad Dermatol 1994;31:1070-2. 
115. Santander C, De Castro M, García Monzón C. Prevalence of hepatitis $C$ virus infection and liver damage in patients with lichen planus. Hepatology 1994; 20: 238A. (Abstract).

116. Protzer U, Ochendorf FR, Leopolder- Ochendorf $\mathrm{A}$, Holtermuller $\mathrm{KH}$. Exarcerbation of lichen planus during interferon alfa-2a therapy for chronic active hepatitis C. Gastroenterology 1993;104:903-5.

117. Seoane Lestón JM, Sanchez López M, Romero Méndez MA, y cols. Liquen plano de la mucosa oral en el curso clínico de una hepatitis crónica activa. Presentación de dos casos. Av Odontoestomatol 1991;7:109-12.

118. Perales Teijo I, Viñuela Sandoval J, Rioboó García R. Etiopatogenia del liquen plano. Revisión. Arch Odontoestomatol 1987;4:3-8.

119. Blanco Carrión A, Otero Rey E, Diniz Freitas M, Antúnez López J, García García A, Gándara Rey JM. Patología sistémica y manifestaciones cutáneas en el liquen plano. Av Odontoestomatol 2002;18:562-71.

120. Helander SD, Rogers RS. The sensitivity and specificity of direct immunofluorescence testing in disorders of mucous membranes. J Am Acad Dermatol 1994;30:65-75.

121. Bagán JV, Alapont L, Milian MA y cols. Inmunofluorescencia directa del liquen plano oral. Estudio de 20 casos. Arch Odontoestomatol 1988;4:353-6.

122. Abell E, Presbury DGC, Marks R. The diagnostic significances of immunoglobulins and fibrin deposition in lichen planus. Br J Dermatol 1975; 93:17-24.

123. Schoidt M, Holmstrup P, Dabelsteen E. Deposits of immunoglobulins, complement and fibrinogen in oral lupus erythematosus, lichen planus and leukoplakia. Oral Surg Oral Med Oral Pathol 1981;51:603-8.

124. Laskaris G, Sklavanou A, Angelopoulos A. Directs immunofluorescence in oral lichen planus. Oral Surg Oral Med Oral Pathol 1981; 53:483-7.

125. Goldstein BH, Katz SM. Immunofluorescent findings in oral bullous lichen planus. J Oral Med 1979;34:8-12.

126. Toto PD, Namidi HT. An Immunohistochemical study of oral lichen planus. Oral Surg Oral Med Oral Pathol 1987;63:60-7.

127. Rogers RS, Sheridan PJ, Nightingale SH. Desquamative gingivitis: clinical, histopathologic, immunopathologic, and therapeutic observations. J Am Acad Dermatol 1982;2: 729-35.

128. Nisegard RJ, Rogers RS. The treatment of desquamative gingival lesions. J Periodontol 1987;58:167-72.

129. Olsen RG, Du Plesis DP, Shulz EJ, Camisa C. Indirect immunofluorescence microscopy of lichen planus. Br J Dermatol 1984;110:9-15.

130. Olsen RG, Du Plesis DP, Shulz EJ, Camisa C. Lichen planus dermophaty: Demostration of lichen planus specific epidermal antigen in affected patient. J Clin Lab Immunol 1983;10:103-6.

131. Bagán JV, Alapont L, Milian MD y cols. Estudio mediante la técnica de inmunofluorescencia indirecta de determinantes antigénicos anómalos en el liquen plano oral. Arch Odontoestomatol 1988;4:357-60.

132. Carrizosa AM, Elorza FL, Camacho FM. Antinuclear antibodies in patients with lichen planus. Exp Dermatol 1997;6:54-6.

133. Bagán JV, Peydro A, Vera FJ. Estudio ultraestructural del liquen plano oral. Análisis de 10 casos. Arch Odontoestomatol 1988;4:9-14.

134. Eady RAJ, Cowen T. Half and half cells in lichen planus. Br J Dermatol 1978;98:417-23.

135. Bagán JV. Liquen plano oral. En: Bagán JV, Vera Sempere F. Patología de la mucosa oral. Barcelona: Syntex Latino SA, 1989:84-91. 
136. Hirota J, Osaki T. Electron microscopy study on cell to cell interaction in oral lichen planus. Path Res Pract 1992;188:1033-41.

137. Sklar E, Flynn E, Szabo Y. Bassement membrane alterations in oral lichen planus. J Invest Dermatol 1978;70:45-50.

138. Finne K, Göransson K, Winkler L. Oral lichen planus and contact allergy to mercury. Int $\mathrm{J}$ Oral Surg 1982;11:236-9.

139. Hietanen J, Philmank K, Förstrom L, Linder E, Reunala T. No evidence of hypersensitivity to dental restorative metals in oral lichen planus. Scand J Dent Res 1987;95:320-7.

140. James J, Ferguson MM, Forsyth A, Tulloch N, Lamey P-J. Oral Lichenoid reactions related to mercury sensitivity. Br J Oral Maxillofac Surg 1987;25:474-80.

141. Bolewska J, Hansen HJ, Holmstrup P, Pindborg JJ, Stangerud M. Oral mucosal lesions related to silver amalgam restorations. Oral Surg Oral Med Oral Pathol 1990;70:55-8.

142. Skloglund A. Value of epicutaneous patch testing in patients with oral mucosal lesions of lichenoid character.Scan J Dent Res 1994;102: 216-22.

143. Sugerman PB, Savage NW, Williams SL, Joynson OB, Daley TJ, Cowpe JG. A quantitative cytological study of lesional and non-lesional mucosa in oral lichen planus. Arch Oral Biol 1996; 41:117-20.

144. Mollaoglu N, Cowpe JG, Walker R. Quantitative cytomorphologic analyses of Papanicolaou- stained smears from oral lichen planus. Anal Quant Cytol Histol 2001;23:118-22.

145. Rode M, Flezar MS, Kogoj-Rode M, Us-Krasovec M. Image cytometric evaluation of nuclear texture features and DNA content of the reticular form of oral lichen planus. Anal Quant Cytol Histol 2006;28:262-8.

146. Orfao A, González Buitrago JM. Citometría de flujo en el laboratorio. Ed Sociedad Española de Bioquímica Clínica y Patología molecular. Madrid 1995.

147. Ahmed AR, Schreiber P, Abramovits W. Coexistence of lichen planus and systemic lupus erithematousus. J Am Acad Dermatol 1982; 7:478-83.

148. Ram S, Siar $\mathrm{CH}$. Chemiluminescence as a diagnostic aid in the detection of oral cancer and potentially malignant epithelial lesions. Int J Oral Maxillofac Surg 2005;34:521-7.

149. Scardina GA, Picone V, Cacioppo A, Messina P. Study of microcirculation in oral lichen planus by video-capillaroscopy. Oral Surg Oral Med Oral Pathol Oral Radiol Endod 2007;103: 30-4.

150. Yan SK, Wei BJ, Lin ZY, Yang Y, Zhou ZT, Zhang WD. A metabonomic approach to the diagnosis of oral squamous cell carcinoma, oral lichen planus and oral leukoplakia. Oral Oncol 2007 (en prensa).

\section{CORRESPONDENCIA}

Andrés Blanco Carrión

Rep. de El Salvador 4, $1^{\circ} \mathrm{C}$

15702 Santiago de Compostela

ablancoc@infomed.es 